\title{
A Neurovascular Niche for Neurogenesis after Stroke
}

\author{
John J. Ohab, ${ }^{1}$ Sheila Fleming, ${ }^{1}$ Armin Blesch, ${ }^{2}$ and S. Thomas Carmichael ${ }^{1}$ \\ ${ }^{1}$ Department of Neurology, University of California, Los Angeles, Los Angeles, California 90095-1735, and ${ }^{2}$ Department of Neuroscience, University of \\ California, San Diego, La Jolla, California 92093-0626
}

\begin{abstract}
Stroke causes cell death but also birth and migration of new neurons within sites of ischemic damage. The cellular environment that induces neuronal regeneration and migration after stroke has not been defined. We have used a model of long-distance migration of newly born neurons from the subventricular zone to cortex after stroke to define the cellular cues that induce neuronal regeneration after CNS injury. Mitotic, genetic, and viral labeling and chemokine/growth factor gain- and loss-of-function studies show that stroke induces neurogenesis from a GFAP-expressing progenitor cell in the subventricular zone and migration of newly born neurons into a unique neurovascular niche in peri-infarct cortex. Within this neurovascular niche, newly born, immature neurons closely associate with the remodeling vasculature. Neurogenesis and angiogenesis are causally linked through vascular production of stromal-derived factor 1 (SDF1) and angiopoietin 1 (Ang1). Furthermore, SDF1 and Ang1 promote post-stroke neuroblast migration and behavioral recovery. These experiments define a novel brain environment for neuronal regeneration after stroke and identify molecular mechanisms that are shared between angiogenesis and neurogenesis during functional recovery from brain injury.
\end{abstract}

Key words: regeneration; neurovascular coupling; hypoxia-ischemia; neurogenesis; stem cells; functional recovery

\section{Introduction}

Stroke causes a localized process of ischemic cell death in the brain, but it also triggers a regenerative response in the tissue adjacent to this area of cell death. Stroke induces the proliferation of endogenous neural progenitor cells and an increase in the number of immature neurons in the subventricular zone (SVZ) (Jin et al., 2001; Arvidsson et al., 2002; Parent et al., 2002; Zhang et al., 2004). Within the first 2-4 weeks after stroke, newly born, immature neurons are present in tissue adjacent to the stroke site. Newly born cells adjacent to the stroke site go on to express phenotypic markers of mature neurons, including neuronalspecific nuclear protein (NeuN), and region-specific mature neuronal markers, such as calbindin and dopamine and cAMPregulated phosphoprotein-32 (Arvidsson et al., 2002; Parent et al., 2002), and form synapses (Yamashita et al., 2006). An understanding of the cellular mechanisms that underlie this neuronal regeneration may lead to novel therapies that promote neural repair after CNS injury.

Post-stroke neurogenesis induces migration of neuroblasts into regions of degenerating striatum that border the SVZ. Im-

\footnotetext{
Received July 24, 2006; revised Nov. 6, 2006; accepted Nov. 7, 2006.

This work was supported by American Heart Association Grant 0555013Y, National Institutes of Health Grant NS053957, and a Distinguished Scholar Award from the Larry L. Hillblom Foundation. J.J.0. is supported by a Ruth L. Kirschstein National Research Service Award. We thank Drs. Michael Sofroniew and Luisa Iruela-Arispe (University of California, Los Angeles, Los Angeles, (A) for the GFAP and VE-cadherin reporter mice and for helpful discussions throughout these experiments, Dr. Dan Dumont (Sunnybrook and Women's Research Institute, Toronto, Ontario, Canada) for providing the Tek4 antibody, Dr. Edward Hoover (Colorado State University, Ft. Collins, (0) for providing the AMD3100, and Jimmy Nguyen, Amanda De La Cerda, Pedrom Sioshansi, Justine Overman, Jessica Wagoner, Jessica Yan, and Cecily Chan for assistance in immunohistochemical staining and behavioral analysis.

Correspondence should be addressed to Dr. S. Thomas Carmichael, Department of Neurology, Geffen School of Medicine at University of California, Los Angeles, 710 Westwood Plaza, Los Angeles, CA 90095. E-mail: scarmichae@@mednet.ucla.edu.

DOI:10.1523/JNEUROSCI.4323-06.2006

Copyright $\odot 2006$ Society for Neuroscience $\quad 0270-6474 / 06 / 2613007-10 \$ 15.00 / 0$
}

mature neurons migrate in chains from the SVZ through portions of the striatum near the SVZ that typically degenerate in most rodent stroke models. This neuroblast migration occurs in association with reactive astrocytes and blood vessels (Thored et al., 2006; Yamashita et al., 2006). However, stroke can induce a long-distance migration of newly born immature neurons to peri-infarct cortex in experimental stroke models (Jin et al., 2003; Tsai et al., 2006). This migration is a remarkable process in the adult brain, because immature neurons cross tissue boundaries of striatum, white matter, and cortex and travel up to $4 \mathrm{~mm}$ through the adult brain from the SVZ (Tsai et al., 2006). Recent evidence suggests that a similar long-distance migration of neuroblasts may occur in peri-infarct tissue in human stroke (Jin et al., 2006). The cellular and molecular mechanisms that mediate such a longdistance migration of newly born immature neurons after stroke have not been defined.

To characterize the cellular source, migratory path, and signaling systems that lead to post-stroke neurogenesis in periinfarct cortex, we used a model of focal stroke in the mouse somatosensory barrel field cortex (Carmichael, 2005; Tsai et al., 2006). In this model, newly born, immature neurons are present in large numbers in peri-infarct cortex in the first week after stroke at distances of 1-4 mm from the SVZ (Tsai et al., 2006). Using a combination of mitotic, genetic, and viral labeling and chemokine/growth factor gain- and loss-of-function studies, we show that stroke induces neuronal regeneration and migration from a GFAP-expressing progenitor cell in the SVZ into a unique "neurovascular niche" in peri-infarct cortex. Within this niche, angiogenesis is casually linked to neurogenesis. Blood vessels in this niche upregulate stromal-derived factor 1 (SDF1) and angiopoietin 1 (Ang1) after stroke, and the tropic action of these two molecules through their receptors recruits thousands of immature neurons into peri-infarct cortex. Administration of Ang1 or 
SDF1 $\beta$ improves behavioral recovery during the period of immature neuron migration.

\section{Materials and Methods}

Animals. Two-month-old C57BL/6 (Charles River Laboratories, Wilmington, MA), enhanced green fluorescent protein (eGFP)-GFAP-cre transgenic mice (Garcia et al., 2004), and $\beta$-galactosidase-vascular endothelial-cadherin-cre transgenic mice (Alva et al., 2006) were used. All procedures were performed in accordance with National Institutes of Health Animal Protection Guidelines. Focal cortical strokes were produced using a previously described model of permanent distal middle cerebral artery occlusion and transient bilateral common carotid occlusion in which body temperature is controlled at $37 \pm 0.5^{\circ} \mathrm{C}$ (Tsai et al., 2006). In this model, ischemic cellular damage is localized to somatosensory and motor cortex (Carmichael, 2005) (supplemental Methods and supplemental Fig. 1, available at www.jneurosci.org as supplemental material).

Bromodeoxyuridine. Bromodeoxyuridine (BrdU) $(50 \mathrm{mg} / \mathrm{kg}$ in $0.9 \%$ saline, i.p.; Sigma, St. Louis, MO) was given every $12 \mathrm{~h}$ during days 1-3 or 1-7 after stroke. For SVZ microinjections, $30 \mathrm{nl}$ of $\mathrm{BrdU}(10 \mathrm{mg} / \mathrm{ml})$ was pressure injected into the SVZ at the time of stroke using stereotaxic coordinates modified for the SVZ (Kirschenbaum et al., 1999). For periinfarct cortex, two injections of $100 \mathrm{nl}$ were made into peri-infarct cortex (anteroposterior, 1.0 and mediolateral, 1.5; anteroposterior, 1.5 and mediolateral, 1.5) (Paxinos and Franklin, 2001) at the time of stroke.

Lentivirus injections. A third generation self-inactivating lentiviral construct expressing GFP under the control of a cytomegalovirus/ $\beta$-actin hybrid promoter was injected at a concentration of $8.5 \times 10^{8} \mathrm{IU} / \mathrm{ml}$ in 30 $\mathrm{nl}$ amounts into the SVZ $2 \mathrm{~d}$ before stroke.

Immunohistochemistry and lectin administration. Fluorescein-labeled Lycopersicon esculentum (Vector Laboratories, Burlingame, CA) was given into the cardiac ventricle during terminal anesthesia $2 \mathrm{~min}$ before the animals were killed (Hashizume et al., 2000). Brains were perfused with $4 \%$ paraformaldehyde, cryoprotected, and frozen. Sections analyzed with bright-field microscopy were incubated in biotinylated secondary antibodies [1:200, $\mathrm{F}(\mathrm{ab})_{2}$; Jackson ImmunoResearch, West Grove, PA] and visualized with the avidin-biotin peroxidase technique (Vector Laboratories). Sections analyzed with epifluorescence and confocal microscopy were incubated in cyanine 2 (Cy2)-, Cy3-, and Cy5conjugated secondary antibodies $\left[1: 200, \mathrm{~F}(\mathrm{ab})_{2}\right.$; Jackson ImmunoResearch]. Primary antibodies were as follows: goat anti-doublecortin (DCX) (C18, 1:500; Santa Cruz Biotechnology, Santa Cruz, CA); rat anti-BrdU (1:300; Abcam, Cambridge, MA); mouse anti-BrdU (1:1000; Chemicon, Temecula, CA); mouse anti-polysialylated neural cell adhesion molecule (PSA-NCAM) (1:400; Chemicon); mouse anti-CXCchemokine receptor-4 (CXCR4) (1:200; PharMingen, San Diego, CA); goat anti-SDF1 (1:100; Santa Cruz Biotechnology); rat anti-plateletendothelial cell adhesion molecule-1 (PECAM-1) (1:300; BD PharMingen, San Diego, CA); rabbit anti-laminin (1:50; Sigma); rabbit anti- $\beta$ galactosidase (1:500; Abcam); rabbit anti-GFAP (1:1000; Zymed, San Francisco, CA); rabbit anti-NG2 (1:400; Chemicon); goat anti-Tie2 (1: 200, Tek4; gift from Dr. Dan Dumont, Sunnybrook and Women's Research Institute, Toronto, Ontario, Canada); goat anti-Ang1 (1:100; Santa Cruz Biotechnology); mouse anti-OX-42 (1:100; Abcam); and mouse anti-glutathione $S$-transferase (GST)- $\pi$ (1:100; BD Biosciences, San Jose, CA). Sections stained for BrdU were pretreated with $2 \mathrm{~N} \mathrm{HCl}$ for $30 \mathrm{~min}$ and neutralized with sodium borate buffer, $\mathrm{pH}$ 8.4, before incubation in primary antibody (Tsai et al., 2006). Sections stained for laminin were pretreated by boiling in distilled water (Casella et al., 2002).

Endostatin. Recombinant mouse endostatin ( $100 \mu \mathrm{g} / \mathrm{ml}$; Alpha Diagnostic, San Antonio, TX) was given as a single daily subcutaneous injection (Dobryansky et al., 2004) during days 1-7 after stroke. Cells double labeled for BrdU and PECAM were quantified in three fields of $0.1 \mathrm{~mm}^{2}$ in peri-infarct cortex in three sections spaced equally through the anterior/posterior SVZ (Tsai et al., 2006). Cells were quantified in vehicleand endostatin-treated animals that received BrdU days 1-7 after stroke and survived to day 7 after stroke. Colocalization of BrdU and PECAM-1 was confirmed with confocal microscopy and $z$-plane reconstruction. Vascular density was quantified in the same tissue sections by tracing
PECAM-1-positive $\left(\mathrm{PECAM}^{+}\right)$blood vessels in fields of $0.3 \mathrm{~mm}^{2}$ at the infarct core/penumbral interface.

Neurovascular ligand gain- and loss-of-function experiments. To test blood-brain barrier (BBB) permeability after stroke, $200 \mu \mathrm{l}$ of $4 \%(\mathrm{w} / \mathrm{v})$ Evans blue (Sigma) in $0.9 \%$ saline was injected intravenously ( $\mathrm{Li}$ et al., 2003) at day 7 or 14 after stroke, animals were perfused $1 \mathrm{~h}$ later, and their brains were frozen and processed for the presence of Evans blue. To test the delivery of vascular ligands, Ang1, SDF1 $\beta$, and receptor-blocking anti-mouse Tie2 antibody ( $1 \mathrm{mg} / \mathrm{ml}$; R \& D Systems, Minneapolis, MN) were conjugated to biotin (Invitrogen, Carlsbad, CA) and delivered via osmotic minipumps (0.5 $\mu \mathrm{l} / \mathrm{h}$; model 1007D; Alzet, Cupertino, CA). Animals were killed 3, 5, and $7 \mathrm{~d}$ after stroke ( $n=3$, each time point), and their brains were frozen and processed for the presence of biotin-labeled protein using Alexa488-conjugated streptavidin (Invitrogen). For gainand loss-of-function experiments, osmotic minipumps were filled with low and high doses of recombinant Ang $1(0.05 \mu \mathrm{g} / 100 \mu \mathrm{l}$ and $0.5 \mu \mathrm{g} / 100$ $\mu \mathrm{l})$, receptor-blocking anti-mouse Tie2 antibody $(1 \mu \mathrm{g} / 100 \mu \mathrm{l}$ and 10 $\mu \mathrm{g} / 100 \mu \mathrm{l})$, recombinant $\operatorname{SDF} 1 \beta(0.27 \mu \mathrm{g} / 100 \mu \mathrm{l}$ and $2.7 \mu \mathrm{g} / 100 \mu \mathrm{l})$, and the CXCR4 receptor antagonist AMD3100 (1.5 mg/100 $\mu \mathrm{l}$ and $5 \mathrm{mg} / 100$ $\mu \mathrm{l}$; gift from Dr. Edward Hoover, Colorado State University, Fort Collins, CO), based on published results (Witzenbichler et al., 1998; Herodin et al., 2003; Roviezzo et al., 2005). Control stroke and sham animals received vehicle (0.1 M NaPBS, $\mathrm{pH} 7.4)$.

Stereology. Five serial sections, spaced $150 \mu \mathrm{m}$ apart, through the SVZ and olfactory bulb (OB) were quantified with the unbiased optical fractionator approach (Tsai et al., 2006) (StereoInvestigator; MicroBrightField, Colchester, VT). Peri-infarct cortex was defined by a $500 \mu \mathrm{m}$ boundary extending from the edge of the infarct core, medial and lateral to the infarct. In OB counts, cells were counted from the cellular layers of the bulb ipsilateral to stroke or in the left $\mathrm{OB}$ in non-stroke animals. Volume of infarction and $\mathrm{DCX}^{+}$cell distribution were measured $7 \mathrm{~d}$ after stroke using previously published methods (Tsai et al., 2006).

Migration vector and white matter analysis. The location of all $\mathrm{DCX}^{+}$ cells in white matter between the SVZ and cortex were plotted in sections spaced $150 \mu \mathrm{m}$ apart through the SVZ. For each treatment condition, the $x-y$ coordinate of every $\mathrm{DCX}^{+}$cell was converted into an equivalent polar coordinate (Carmichael et al., 2001; Dancause et al., 2005) $(r, \theta)$ using the dorsolateral edge of the ventricle as the origin. The location of each cell in each brain in each treatment condition was then transferred to a common polar space, and a mean migration vector was computed for that treatment. The migration vector is defined by the angle of migration $(\theta)$ and distance (length of vector, $r$ ) from the SVZ through subcortical white matter for each condition (Carmichael et al., 2001; Dancause et al., 2005). Migration vectors did not differ between low- and high-dose treatments in any condition (supplemental Fig. 2, available at www.jneurosci.org as supplemental material), so these groups were combined. For white matter counts, the number of cells plotted for the migration vector analysis was averaged per section for each treatment condition.

Behavioral analysis. Mice were tested on a whisker-guided forelimb extension task modified from Gerlai et al. (2000). Facial vibrissae were stimulated by gently lowering the animal by the tail toward a horizontal surface. As the vibrissae contact the surface, the animal responds by extending its forelimbs. Forelimb extensions were recorded for three trials per animal by an observer blind to treatment condition.

Statistics. DCX cortical and white matter cell number and volume and infarct size were tested with factorial ANOVA and Bonferroni's (Statview 5.0.1; SAS Institute, Cary, NC) or Tukey-Kramer post hoc testing (see above, Behavioral analysis). ANOVA values are in supplemental Table 1 (available at www.jneurosci.org as supplemental material). Vascular density, $\mathrm{BrdU}{ }^{+} / \mathrm{PECAM}-{ }^{+}$cell number, infarct volume, and DCX cell counts in endostatin versus vehicle were tested with two-sample paired $t$ test assuming unequal variance (Excel; Microsoft, Seattle, WA). Migration vector angles were evaluated for statistical significance using the Watson-Williams $F$ test (Dancause et al., 2005) (Oriana version 2.02a; Kovach Computer Services, Anglesey, UK), and migration vector lengths were compared separately between vehicle and each combined treatment group with two-sample paired $t$ test assuming unequal variance (Excel; Microsoft). 

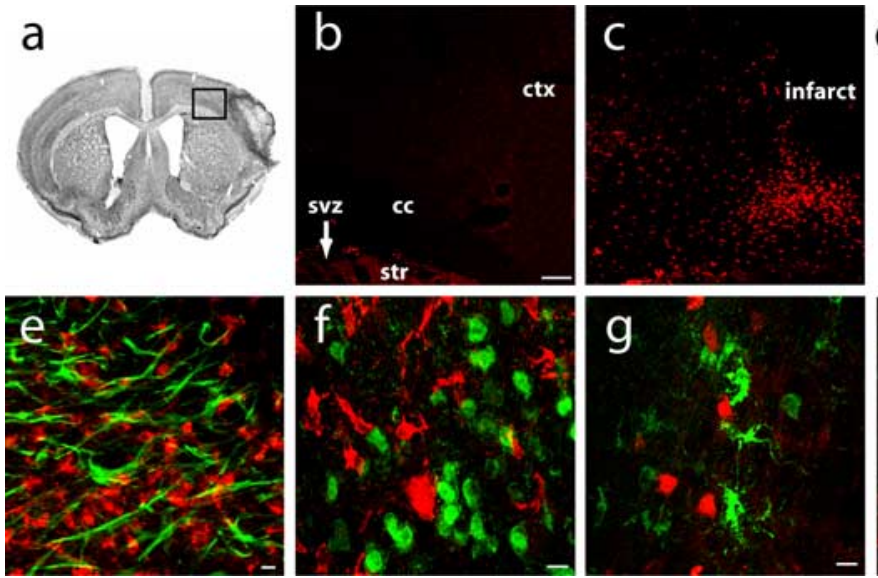

Figure 1. Focal cortical stroke induces neuroblast localization in peri-infarct cortex. $\boldsymbol{a}$, cresyl violet section through frontal cortex after stroke. $\boldsymbol{b}, \boldsymbol{c}, \mathrm{DCX}{ }^{+}$cells (red) in non-stroke $(\boldsymbol{b})$ and day 7 post-stroke (c) taken from region of box in $\boldsymbol{a}$. Scale bar, 100 $\mu \mathrm{m} . \boldsymbol{d}$, Stereological quantification of $D C X^{+}$cells in peri-infarct cortex at day 7 after stroke. $p<0.04$ for day 3 versus control, not significant by Bonferroni's post hoc testing; $p<0.0001$ for day 7 versus control and day 3.e, $\boldsymbol{f}, \mathrm{DCX}^{+}$cells (red) do not colocalize with GFAP ${ }^{+}\left(\boldsymbol{e}\right.$, green) or NeuN $^{+}$cells $\left(\boldsymbol{f}\right.$, green) in peri-infarct cortex. Scale bar, $25 \mu \mathrm{m} . \boldsymbol{g}, \mathrm{DCX}^{+}$cells (green) do not colocalize with $\mathrm{NG2}^{+}$cells (red) in peri-infarct cortex. Scale bar, $25 \mu \mathrm{m} . \boldsymbol{h}, \mathrm{DCX}{ }^{+}$cells (red) do not colocalize with GST $\pi^{+}$(green) cells in peri-infarct cortex. Scale bar, $25 \mu \mathrm{m}$. ${ }^{*} p<0.0001$; ${ }^{\#} p<0.0001$. Error bars indicate SD. cc, Corpus callosum; ctx, cortex; str, striatum.
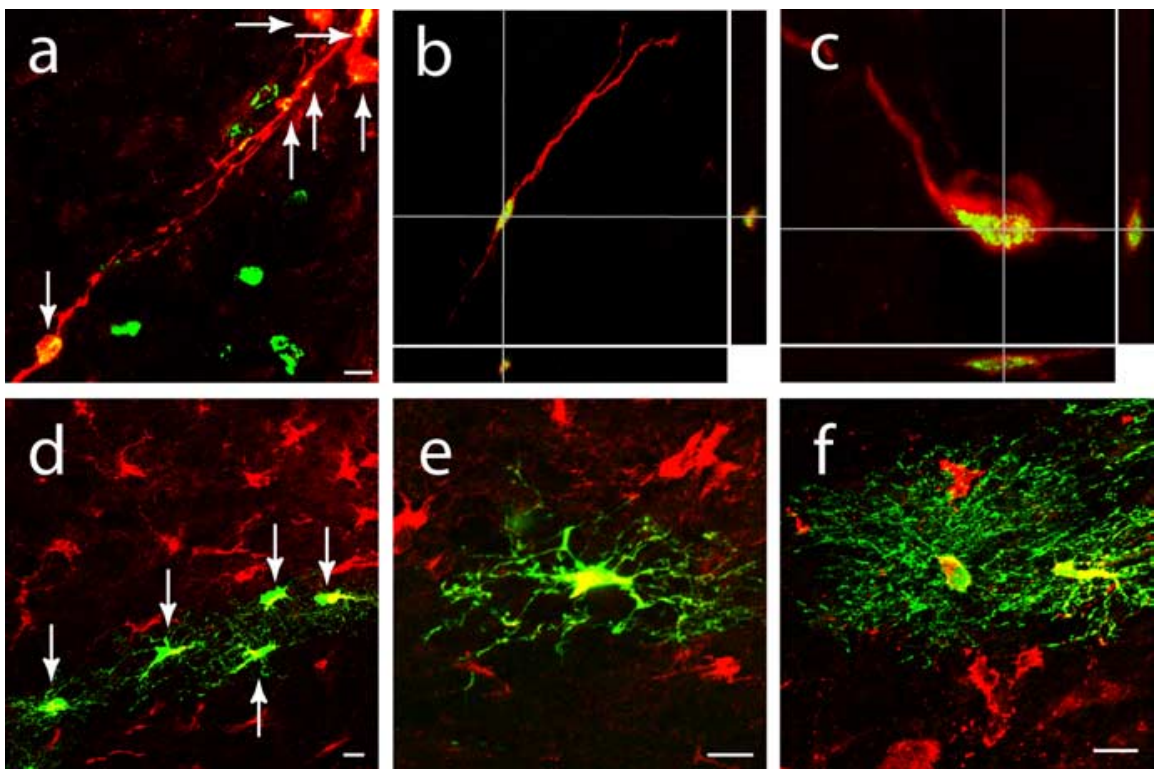

Figure 2. Newly born neuroblasts migrate from the SVZ to peri-infarct cortex after stroke. $\boldsymbol{a}-\boldsymbol{c}$, Cells double labeled (arrows) for DCX (red), BrdU (green), and overlap (yellow) in white matter (b), the white matter/cortical interface (a), and peri-infarct cortex (c) at day 7 after stroke after SVZ microinjection of BrdU. Three-dimensional confocal reconstructions of cells in $\boldsymbol{b}$ and $\boldsymbol{c}$ are presented as viewed in the $x-z$ (bottom) and $y-z$ (right) planes. $\boldsymbol{d}, \boldsymbol{e}$, Cells double labeled (arrows) for DCX (red) and GFP (green) migrate through peri-infarct cortex at day 7 after stroke after SVZ microinjection of lentivirus/GFP.f, Cells double labeled for DCX and GFP extending extensive local processes into peri-infarct cortex at day 14 after stroke after SVZ microinjection of lentivirus/ GFP. Scale bars, $25 \mu \mathrm{m}$.

\section{Results}

\section{Newly born neuroblasts migrate from SVZ to peri-infarct} cortex after stroke

Focal cortical stroke in this model is restricted to the frontal and parietal cortex, involving the somatosensory barrel cortex and bordering the forelimb sensorimotor cortex (Carmichael, 2005; Tsai et al., 2006). Necrotic and apoptotic cell death and oxidative cellular damage is restricted to cortex and does not involve the underlying white matter, striatum, or SVZ (supplemental Fig. 1, available at www.jneurosci.org as supplemental material). Mi-
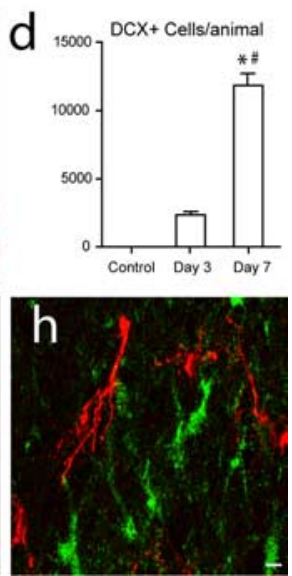

grating immature neurons (neuroblasts) were identified by the microtubuleassociated protein DCX, a specific marker for migratory or immature neurons in the adult brain (Brown et al., 2003; CouillardDespres et al., 2005). DCX $^{+}$cells were not present in cortex in the control, nonstroke mouse (Fig. 1b) (Tsai et al., 2006). Focal cortical stroke induced a large number of newly born $\mathrm{DCX}^{+}$cells first in subcortical white matter and then in periinfarct cortex (Fig. 1c,d). With stereological quantification, there were $1972 \pm 833$ cells in peri-infarct cortex per animal at day 3 after stroke, increasing to $11,789 \pm$ 2081 per animal at day 7 (Fig. $1 d$ ). DCX $^{+}$ cells in white matter and peri-infarct cortex were not immunoreactive for GFAP, NeuN, NG2, GST $\pi$, OX-42, or desmin, markers of mature astrocytes, mature neurons, immature and mature oligodendrocytes, microglia/macrophages, and pericytes (Fig. 1e-h) (supplemental Fig. 3, available at www.jneurosci.org as supplemental material) (Brown et al., 2003; Aguirre and Gallo, 2004; Kokovay et al., 2006), but are immunoreactive for other markers of CNS progenitor cells in this model, such as PSA-NCAM and musashi (Tsai et al., 2006).

Neuroblasts migrate from the SVZ to closely adjacent regions of the striatum (Yamashita et al., 2006). To directly test for neuroblast migration from the SVZ to peri-infarct cortex, BrdU or lentivirus/ GFP was microinjected into the SVZ at the time of the stroke, and labeled cells were analyzed in peri-infarct cortex at days 7 and 14. BrdU and lentivirus/GFP are not axonal tracers, so cells in cortex that are labeled from direct microinjection into SVZ have necessarily migrated from the SVZ (Kirschenbaum et al., 1999). The injection site for lentivirus or BrdU is distant from peri-infarct cortex, passing through cingulate cortex en route to the SVZ at a distance of 2-4 $\mathrm{mm}$ from the peri-infarct cortex (supplemental Fig. 4, available at www.jneurosci.org as supplemental material). Seven days after stroke, $\mathrm{BrdU}^{+} /$ $\mathrm{DCX}^{+}$cells that are labeled from the SVZ exhibited two distinct morphologies. In white matter, $\mathrm{BrdU}^{+} / \mathrm{DCX}^{+}$cells displayed elongated nuclei and bipolar processes (Fig. 2a,b) (Tsai et al., 2006) typical of migrating neuroblasts (Brown et al., 2003). In peri-infarct cortex, $\mathrm{BrdU}^{+} / \mathrm{DCX}^{+}$cells had more rounded cell bodies that contained multiple small processes (Fig. $2 c$ ). Lentivirus injection into the SVZ induced GFP expression in $\mathrm{DCX}^{+}$cells in peri-infarct cortex with dense local neurites at days 7 and 14 after stoke (Fig. $2 d-f$ ). BrdU cellular labeling may occur during DNA repair. To confirm that $\mathrm{BrdU}^{+} / \mathrm{DCX}^{+}$cells in peri-infarct cortex were derived through mitosis and migration from the SVZ, BrdU was directly injected into peri-infarct cortex at six 
times the volume of the SVZ injections. In contrast to direct injection into the SVZ, injection into peri-infarct cortex produced only rare cells double-labeled with BrdU/DCX (supplemental Fig. 4, available at www.jneurosci.org as supplemental material). The small numbers of $\mathrm{DCX}^{+}$cells labeled by BrdU in peri-infarct cortex may indicate cell division in these neural progenitor cells during migration, as occurs in the rostral migratory stream (Gritti et al., 2002). Post-stroke neurogenesis and cortical migration may occur at the expense of normal neuroblast migration from the SVZ to OB. Stereological quantification of newly born cells in $\mathrm{OB}$ confirms this suggestion, because there were $8325 \pm 1274$ cells per OB per animal in control and $5361 \pm 541$ cells per OB per animal after stroke (supplemental Fig. 3, available at www.jneurosci.org as supplemental material) $(p=$ $0.004)$. These data show that newly born neuroblasts migrate from the SVZ to peri-infarct cortex over the first week after stroke in a process that reduces or diverts normal neuroblast migration to the OB.

\section{Post-stroke neurogenesis derives from a GFAP-expressing progenitor cell}

Adult neurogenesis in the SVZ derives from GFAP-expressing progenitor cells (Garcia et al., 2004). However, ischemia mobilizes bone marrow-derived endothelial precursor cells (EPCs) that incorporate into blood vessels after ischemia (Zhang et al., 2002; Hristov and Weber, 2004) and may form neurons in situ near stroke (Hess et al., 2004). Local neurogenesis from the SVZ to the striatum derives from a GFAP expression progenitor (Yamashita et al., 2006). To identify the cellular origin of post-stroke migrating neuroblasts in cortex, strokes were produced in eGFPGFAP-cre reporter mice. In this line, GFP is produced in any cell that has expressed GFAP and then turned off this gene or is currently expressing GFAP (Garcia et al., 2004). Strokes were also produced in mice that express $\beta$-galactosidase through the VEcadherin promoter (Alva et al., 2006). VE-cadherin is expressed in EPCs (Hristov and Weber, 2004). Seven days after stroke, $\mathrm{DCX}^{+}$cells colocalized entirely with GFP expression in periinfarct cortex of GFAP reporter mice (Fig. $3 a, b$ ). DCX ${ }^{+}$cells did not express GFAP after stroke (Fig. 1e), indicating that the $\mathrm{DCX}^{+}$ cells after stroke are derived from a GFAP-expressing progenitor cell. In VE-cadherin reporter mice, $\mathrm{DCX}^{+}$cells did not colocalize with $\beta$-galactosidase expression (Fig. $3 c, d$ ), although $\mathrm{DCX}^{+}$ cells closely associated with VE-cadherin-expressing endothelial cells (Fig. 3d).

\section{Neuroblasts associate with remodeling blood vessels in a neurovascular niche}

Within the normal adult SVZ and subgranular zone (SGZ), neurogenesis occurs in close association with endothelial cells in an environment termed the neurovascular niche (Louissaint et al., 2002; Alvarez-Buylla and Lim, 2004; Wurmser et al., 2004). Within degenerating striatum, $\mathrm{DCX}^{+}$cells appear to migrate along both astrocytes and blood vessels (Thored et al., 2006; Yamashita et al., 2006). Stroke alters the molecular profile of endothelial cells in peri-infarct cortex (Abumiya et al., 1999; Stumm et al., 2002), the site of in-migration of neuroblasts after stroke. We hypothesized that stroke changes the cellular environment in peri-infarct cortex by forming a unique neurovascular niche in which newly born neuroblasts associate with vascular endothelial cells. Tissue sections were stained for DCX or PSA-NCAM and markers of vascular endothelial cells, laminin, von Willebrand factor, and PECAM-1. DCX ${ }^{+}$(Fig. 4a,b) (supplemental Fig. 5, available at www.jneurosci.org as supplemental material) and
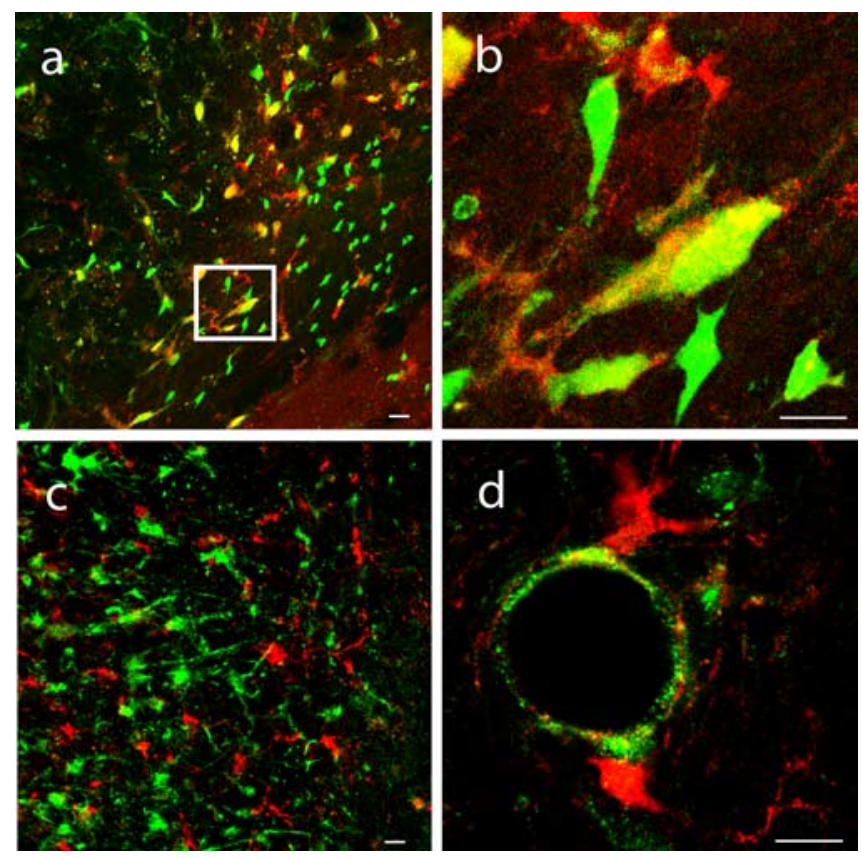

Figure 3. Post-stroke neurogenesis derives from a GFAP-expressing progenitor in the SVZ.a, $\boldsymbol{b}, D C X^{+}$cells (red) colocalize entirely with GFP (green) expression in peri-infarct cortex of GFAP reporter mice producing large regions of overlap (yellow). A subpopulation of GFP ${ }^{+} / D C X$ negative cells is presumed to be astrocytes. The region within the box in $\boldsymbol{a}$ is enlarged in $\boldsymbol{b}$. Scale bars, $25 \mu \mathrm{m}$. c, DCX ${ }^{+}$cells (red) do not colocalize with $\beta$-galactosidase expression (green) in peri-infarct cortex of VE-cadherin reporter mice. Scale bar, $25 \mu \mathrm{m} . \boldsymbol{d}, \mathrm{DCX}{ }^{+}$cells (red) are located in close physical proximity to $\beta$-galactosidase ${ }^{+}$endothelial cells (green). Scale bar, $25 \mu \mathrm{m}$.

PSA-NCAM $^{+}$(Fig. 4c) cells were always located in close physical proximity to endothelial cells in peri-infarct cortex, in which they interdigitated within the folds of the blood vessel and ensheathed the vascular endothelial cell (Fig. $4 d, e$ ).

As blood vessels grow and branch, they do not initially receive vascular perfusion (Ware and Simons, 1997). Using this process, the vascular anatomy of the peri-infarct cortex was defined by staining all endothelial cells with PECAM-1 and staining those that receive vascular perfusion with intravital administration of Lycopersicon esculentum (Hashizume et al., 2000). At $7 \mathrm{~d}$ after stroke, a region of peri-infarct cortex contained vessels with small branches and sprouts that did not yet receive vascular flow (Fig. $5 a-e)$. This region of vascular remodeling is the site of inmigration of $\mathrm{DCX}^{+}$cells in peri-infarct cortex (Fig. $5 a-e$ ). In control cortex, all vascular endothelial cells colabeled with Lycopersicon esculentum, and $\mathrm{DCX}^{+}$cells were not present (supplemental Fig. 5, available at www.jneurosci.org as supplemental material). This data indicates that neuroblasts migrate not just to blood vessels in peri-infarct cortex but to areas of active vascular remodeling after stroke.

\section{Angiogenesis and neurogenesis are causally linked within the} post-stroke neurovascular niche

Angiogenesis is associated with neurogenesis in the SVZ and SGZ (Leventhal et al., 1999; Alvarez-Buylla and Lim, 2004; Wurmser et al., 2004), but a direct link between these two processes has not been shown in other brain regions, in either the normal or stroke state. To first correlate these two processes in peri-infarct cortex, animals were given BrdU during days 1-3 after stroke and were killed on day 7. Double labeling for BrdU and PECAM-1 indicates that blood vessels in peri-infarct cortex contain newly born vascular endothelial cells (Fig. 5f) (supplemental Fig. 6, available 

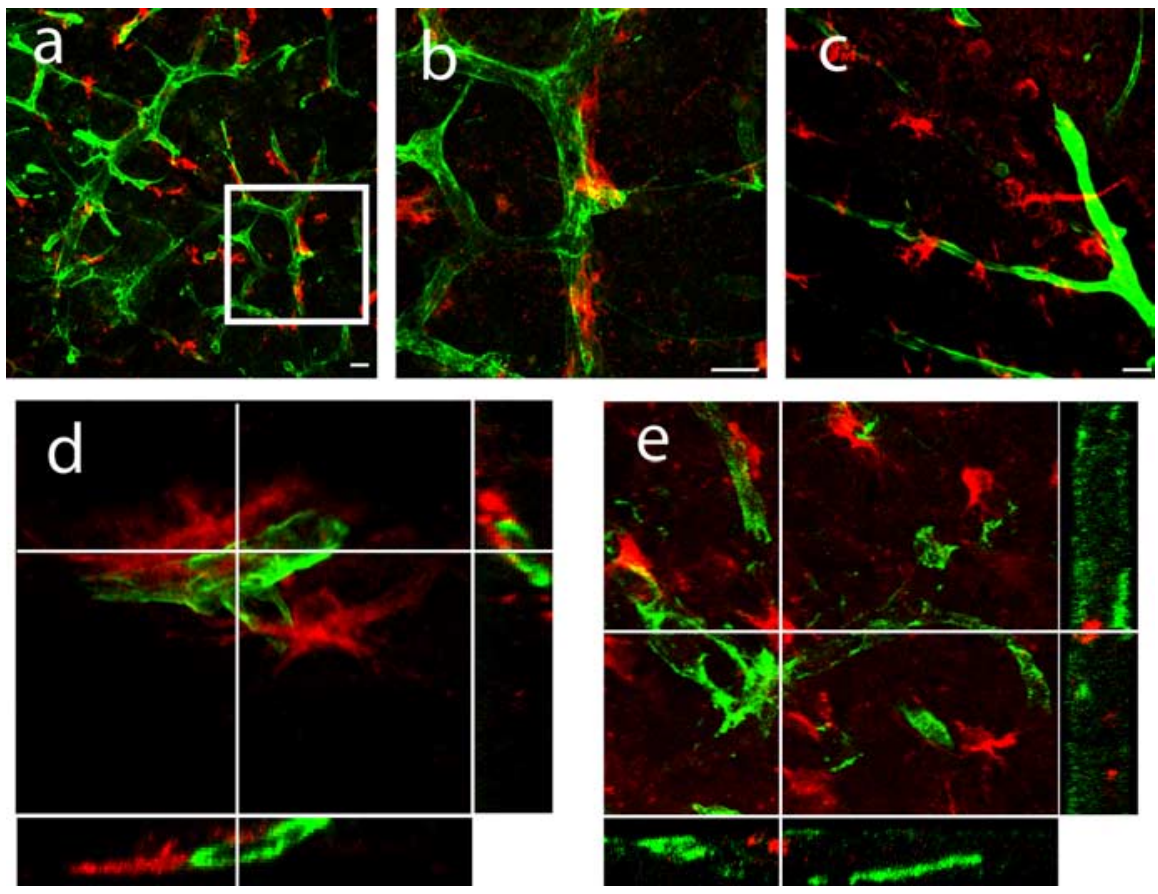

Figure 4. Peri-infarct neuroblasts form close physical associations with vascular endothelial cells. $\boldsymbol{a}, \boldsymbol{b}, \mathrm{DCX}{ }^{+}$cells (red) form close physical associations with peri-infarct blood vessels immunoreactive for laminin (green). The region within the box in $a$ is enlarged in $\boldsymbol{b}$. $\boldsymbol{c}$, PSA-NCAM ${ }^{+}$cells (red) align with endothelial cells stained for PECAM-1 (green). Scale bar, $25 \mu \mathrm{m} . \boldsymbol{d}, \boldsymbol{e}$, Three-dimensional confocal reconstructions demonstrate $D C X^{+}$cells (red) interdigitate within the folds of laminin ${ }^{+}(\boldsymbol{d})$ and PECAM- $1^{+}$endothelial cells $(\boldsymbol{e}$, green) in peri-infarct cortex.

at www.jneurosci.org as supplemental material). Clusters of $\mathrm{BrdU}^{+} / \mathrm{DCX}^{+}$cells were found adjacent to these newly born endothelial cells (Fig. 5f) (supplemental Fig. 6, available at www.jneurosci.org as supplemental material). Thus, neurogenesis and the migration of newly born neuroblasts are coextensive with angiogenesis in peri-infarct cortex after stroke.

We next tested the causal role of angiogenesis in post-stroke neuroblast migration by blocking angiogenesis with endostatin, a direct inhibitor of normal and post-ischemic angiogenesis (Folkman et al., 2001; Dobryansky et al., 2004). Endostatin is a direct angiogenesis inhibitor, whereas other angiogenesis inhibitors indirectly block angiogenesis through an interaction with the vascular endothelial growth factor (VEGF) system, preventing an interpretation of the direct link between angiogenesis and neurogenesis (Folkman et al., 2001). In this model of stroke, 1 week of endostatin treatment resulted in a 74\% decrease in the number of newly born PECAM- ${ }^{+}$endothelial cells $(p<0.003)$ and a $30 \%$ decrease in overall vascular density $(p<0.005)$ in peri-infarct cortex compared with vehicle-treated animals. Endostatin treatment resulted in a 10 -fold reduction in $\mathrm{DCX}^{+}$cells in periinfarct cortex at day 7 after stroke compared with vehicletreated animals (Fig. 5g,h) (supplemental Fig. 6, available at www.jneurosci.org as supplemental material) $(p<0.0001)$. Infarct volume did not vary between endostatin- and vehicletreated animals $(p=0.39)$.

\section{Receptor/ligand signaling in the post-stroke} neurovascular niche

Ang1 and SDF1 are expressed by endothelial cells, upregulated by hypoxia after stroke, and directly regulate stem cell differentiation or migration through their receptors Tie2 and CXCR4 (Jones et al., 2001; Stumm et al., 2002; Arai et al., 2004; Imitola et al., 2004; Robin et al., 2006). This data suggests that the Ang1 and
SDF1 systems may play a role in the poststroke neurovascular niche for inmigrating neuroblasts. In previous studies using xenotransplants of stem/progenitor cells or transplants of conditionally immortalized cell lines, SDF1 is associated with survival and migration of the transplanted cells in the brain (Imitola et al., 2004; Taguchi et al., 2004; Robin et al., 2006). However, xenotransplants and conditionally immortalized cell lines differ substantially from the normal CNS progenitor cell population (Mi et al., 2005) and do not directly reveal a role for SDF1 and Ang1 in the endogenous neural progenitor response after stroke.

Ang1 is induced in blood vessels in peri-infarct cortex from days 3 to 7 after stroke (Fig. 6a,c) (supplemental Fig. 7, available at www.jneurosci.org as supplemental material). Stroke induced Ang1 expression within blood vessels that extend from the infarct core to the SVZ, along the entire pathway of neuroblast migration after stroke (Fig. 6c). Ang1 ${ }^{+}$blood vessels were in close physical proximity to $\mathrm{Tie}^{+}{ }^{+}$/ PSA-NCAM $^{+}$cells in peri-infarct cortex (Fig. 6d). SDF1 was induced within blood vessels throughout the infarct core and peri-infarct cortex maximally at day 3 and persisted through day 7 (Fig. 6b) (supplemental Fig. 7, available at www.jneurosci.org as supplemental material). The SDF1 receptor CXCR4 colocalized with $\mathrm{DCX}^{+}$cells in both white matter and peri-infarct cortex at these time points after stroke (Fig. 6e). These data position Ang1/Tie2 and SDF1/CXCR4 to mediate post-stroke neuroblast migration to peri-infarct cortex.

\section{Gain- and loss-of-function within the neurovascular niche}

Stroke opens the BBB in peri-infarct cortex for up to $90 \mathrm{~d}$ after infarction (Veltkamp et al., 2005; Yu et al., 2006). To establish $\mathrm{BBB}$ permeability in this stroke model, SDF1 $\beta$, Ang1, and a function-blocking anti-Tie2 antibody were labeled by fluorescent conjugation and delivered systemically for $5 \mathrm{~d}$ after stroke. These molecules were present selectively in peri-infarct cortex (supplemental Fig. 8, available at www.jneurosci.org as supplemental material), and this result was confirmed with systemic delivery of Evans blue (supplemental Fig. 8, available at www.jneurosci.org as supplemental material), indicating that, with systemic delivery, molecules can directly permeate the neurovascular niche in peri-infarct cortex during the period of neuroblast migration. To induce or block the SDF1 and Ang1 systems, drugs were delivered systemically for $7 \mathrm{~d}$ after stroke. The SDF1 $\beta$ isoform was chosen because it is selectively induced in blood vessels after stroke (Stumm et al., 2002). Infarct volumes did not vary significantly between vehicle and treatment conditions (supplemental Fig. 8, available at www.jneurosci.org as supplemental material).

Administration of SDF1 $\beta$ caused a dose-specific increase of thousands of additional neuroblasts into peri-infarct cortex (Fig. $7 a-c)(p<0.016)$. DCX ${ }^{+}$cells occupied a nearly twofold greater volume of peri-infarct tissue with SDF $1 \beta$ delivery compared with vehicle (Fig. $7 d)(p=0.0169)$. These $\mathrm{DCX}^{+}$cells clustered specifically around blood vessels (Fig. 7e). Conversely, blockade of CXCR4 with the specific antagonist AMD3100 (De Clercq, 2000) 

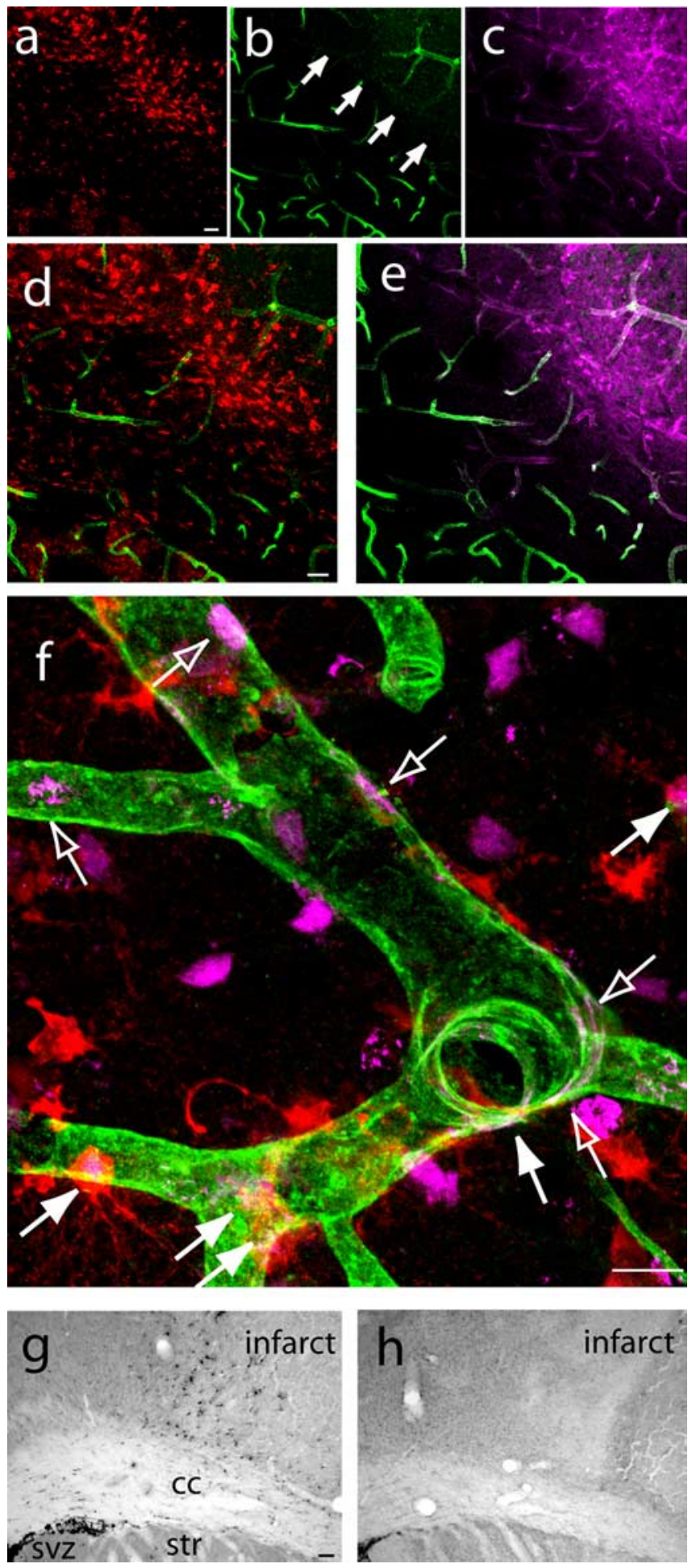

Figure 5. Neurogenesis and angiogenesis are causally linked in a novel neurovascular niche in peri-infarct cortex. $\boldsymbol{a}-\boldsymbol{e}, \mathrm{DCX}{ }^{+}$cells $(\boldsymbol{a})$ localize to a region of vascular remodeling in periinfarct cortex characterized by poor lectin perfusion $(\boldsymbol{b})$ but robust PECAM-1 immunoreactivity (c) at day 5 after stroke. $\boldsymbol{d}$ and e represent merged images of $\boldsymbol{a}, \boldsymbol{b}$ and $\boldsymbol{b}, \boldsymbol{c}$, respectively. Arrows in $\boldsymbol{b}$ indicate the region of poor lectin perfusion adjacent to the infarct core. Scale bars, $50 \mu \mathrm{m}$. $\boldsymbol{f}$, High-magnification confocal image showing that newly born neuroblasts localize in a region of newly born endothelial cells at day 7 after stroke. Filled arrows indicate newly born neuroblasts double labeled for DCX (red) and BrdU (purple), and open arrows indicate newly born endothelial cells double labeled for PECAM-1 (green) and BrdU (purple). Scale bar, $25 \mu \mathrm{m} . \boldsymbol{g}, \boldsymbol{h}, \mathrm{DCX}^{+}$ cells, stained with DAB, are significantly reduced in peri-infarct cortex of endostatin-treated $(\boldsymbol{h})$ compared with vehicle-stroke animals $(\boldsymbol{g})$ at day 7 after stroke. Scale bar, $100 \mu \mathrm{m}$. cc, Corpus callosum; str, striatum. resulted in a dispersal of $\mathrm{DCX}^{+}$cells into a greater volume of peri-infarct cortex, without altering $\mathrm{DCX}^{+}$cell number (Fig. $7 a, c, d)$. Administration of SDF1 $\beta$ or AMD3100 did not alter the number of $\mathrm{DCX}^{+}$cells in white matter (supplemental Fig. 8, available at www.jneurosci.org as supplemental material). However, administration of AMD3100 altered the migratory pathway of neuroblasts after stroke, producing a highly aberrant linear cluster of $\mathrm{DCX}^{+}$cells along the boundary between the corpus callosum and striatum (Fig. $7 b$ ).

To quantify this aberrant neuroblast migration, we computed a migration vector by mapping all $\mathrm{DCX}^{+}$cells between SVZ and cortex into polar coordinates. Administration of AMD3100 resulted in a truncated migratory path through white matter, with a significant $20 \%$ reduction in migration vector length $(p<0.009)$ and a significant dorsal shift in the angle of the migration vector compared with vehicle-stroke animals (Fig. $7 g)(p<4.5 \times$ $\left.10^{-6}\right)$. This quantifies the observation of the ectopic cluster of $\mathrm{DCX}^{+}$cells along the dorsal surface of the striatum with AM3100 administration (Fig. $7 b, g$ ). Administration of SDF1 $\beta$ significantly shifted the migratory vector for $\mathrm{DCX}^{+}$cells ventrally $(p<4.5 \times$ $10^{-6}$ ), toward the stroke, but did not alter its length (Fig. $7 g$ ).

Administration of both high and low doses of Angl resulted in $\sim 5000$ more $\mathrm{DCX}^{+}$cells in peri-infarct cortex compared with vehicle stroke animals (Fig. 7a,c) $(p<0.007)$. After Ang1, $\mathrm{DCX}^{+}$ cells continued to localize in tight association with endothelial cells (Fig. $7 f$ ). DCX ${ }^{+}$cells localized to the same volume of periinfarct tissue in both Ang1 and vehicle-stroke animals (Fig. $7 d$ ) $(p \geq 0.15)$. However, blockade of Tie 2 resulted in a reduction in the volume of distribution of $\mathrm{DCX}^{+}$cells in peri-infarct cortex and a trend toward a reduced number of $\mathrm{DCX}^{+}$cells in periinfarct cortex (Fig. 7a,c,d). Administration of Ang1 and anti-Tie2 antibody did not alter the number of $\mathrm{DCX}^{+}$cells in white matter (supplemental Fig. 8, available at www.jneurosci.org as supplemental material). Vector analysis showed that Ang1 administration shifted the migratory path of $\mathrm{DCX}^{+}$cells ventrally, away from the SVZ, similar to SDF1 $\beta$-treated animals (Fig. $7 g)(p<$ $\left.4.5 \times 10^{-6}\right)$. Surprisingly, administration of anti-Tie 2 shifted the vector angle even farther ventrally by $\sim 8^{\circ}$ compared with vehicle stroke animals $\left(p<4.5 \times 10^{-6}\right)$. Blockade of the Tie2 receptor produced a $10 \%$ reduction in migration vector length compared with vehicle-stroke animals $(p<0.009)$.

\section{Long-term survival}

To determine the long-term survival of regenerating neurons and the effects of SDF1 $\beta$ and Ang1 on this process, animals were administered the two treatments that produced the greatest effect on neuroblast migration, high-dose Ang1 and $\mathrm{SDF} 1 \beta$, as well as vehicle. Stereological quantification of $\mathrm{NeuN}^{+} / \mathrm{BrdU}^{+}$cells in peri-infarct cortex after a 3 month survival showed no difference among conditions (Fig. $8 a$ ). Thus, $\sim 10 \%$ of the initial number of neuroblasts that migrate to peri-infarct cortex survive in the long term (Fig. $8 b$ ). Although SDF1 $\beta$ and Ang1 promote early neuroblast migration to peri-infarct cortex, they do not influence their survival.

\section{Behavioral recovery}

In this model, stroke is produced in a small region of the mouse somatosensory cortex: the barrel field or the representation of the mouse's facial whiskers. Although this cortical stroke is well removed from the SVZ and suited for studying long-distance neuroblast migration, this stroke does not produce significant deficits in motor tests of forelimb or hindlimb postural or exploratory movements or gait (J. J. Ohab, S. Fleming, and S. T. 

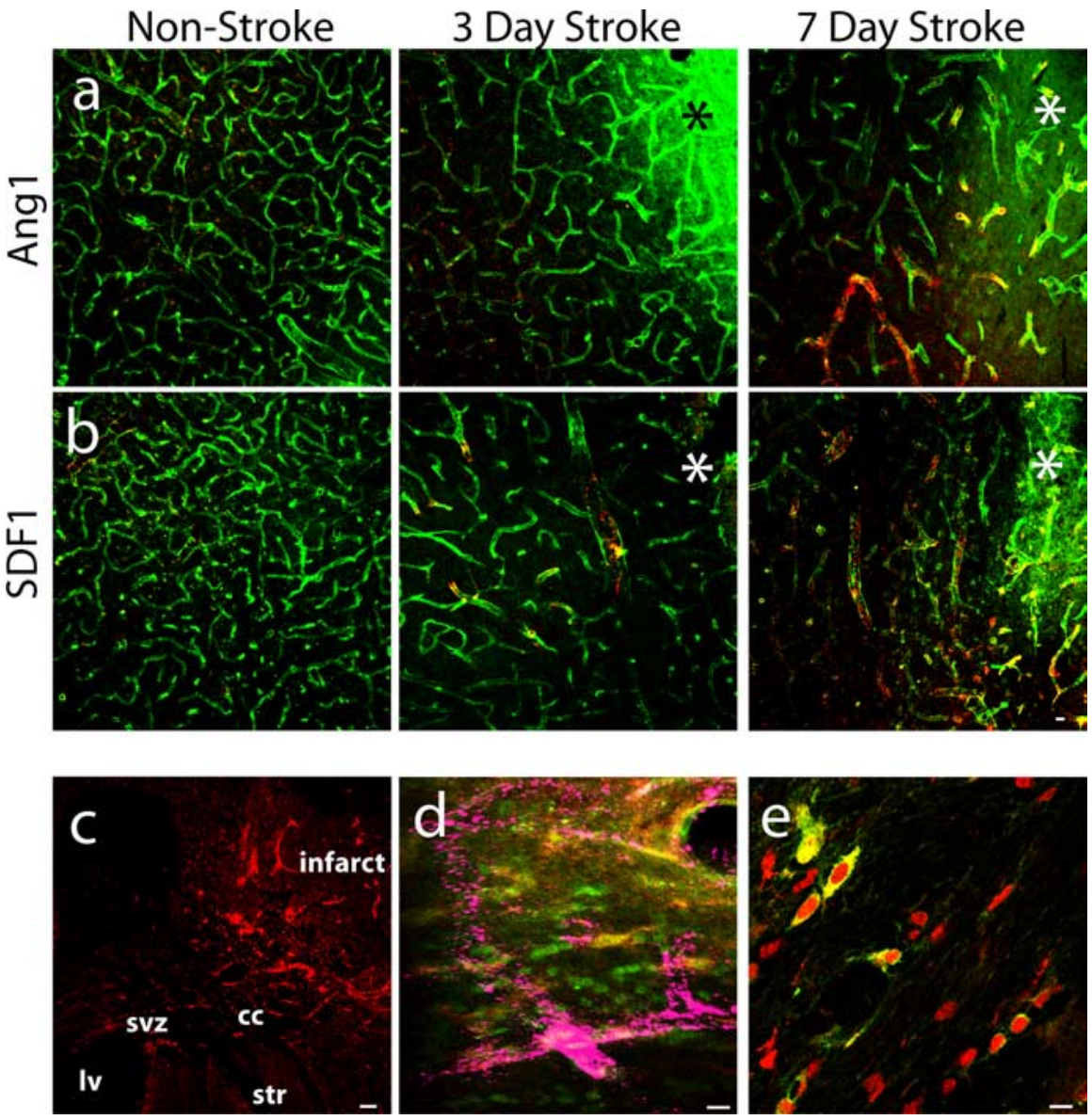

Figure 6. Ang1 and SDF1 are positioned to mediate post-stroke neurogenesis. $\boldsymbol{a}$, Ang1 expression (red) in PECAM- $1^{+}$endothelial cells (green) remains unchanged at $3 \mathrm{~d}$ after stroke and increases at $7 \mathrm{~d}$ after stroke compared with non-stroke animals. Yellow indicates vessels with staining present for both PECAM-1 and Ang1. $\boldsymbol{b}$, SDF1 expression (red) in PECAM- $1^{+}$endothelial cells (green) and overlap (yellow) increases at day 3 after stroke and persists in blood vessels through day 7 after stroke compared with non-stroke animals. Asterisks indicate the region of infarction. Scale bar, $50 \mu \mathrm{m}$. c, Ang1 (red) is expressed along the pathway of neuroblast migration from the SVZ toward the infarct at day 5 after stroke. Scale bar, $60 \mu \mathrm{m}$. $\boldsymbol{d}$, Merged confocal images show that PSA-NCAM ${ }^{+}$cells (red) coexpress the Tie2 receptor (green; PSA-NCAM ${ }^{+} / \mathrm{Tie}^{+}{ }^{+}$cells are yellow) in close proximity to Ang1-expressing blood vessels (purple). Scale bar, $30 \mu \mathrm{m} . \boldsymbol{e}, \mathrm{DCX}{ }^{+}$cells (red) colocalize with the SDF1 receptor CXCR4 (green), producing a large region of overlap (yellow), as they enter peri-infarct cortex at day 7 after stroke. Scale bar, 30 $\mu \mathrm{m}$. cc, Corpus callosum; ctx, cortex; Iv, lateral ventricle; str, striatum.

Carmichael, unpublished observations). To determine the functional effect of neuroblast migration on behavioral recovery, a test of whisker-guided forelimb extension was used (Gerlai et al., 2000). We tested the behavioral effects of the SDF1 $\beta$ and Ang1, because these two treatments produced the greatest effect on neuroblast migration. Stroke plus vehicle infusion produced a deficit in whisker-guided forelimb reaching during the first $10 \mathrm{~d}$ after the stroke (Fig. 8c). Infusion of SDF1 $\beta$ and Ang1 significantly improved this behavioral function to a level indistinguishable from control, non-stroke animals (Fig. $8 c$ ). The time period of this behavioral effect corresponds to the interval in which SDF1 $\beta$ and Ang1 recruit large numbers of additional neuroblasts into periinfarct cortex.

\section{Discussion}

Focal cortical stroke induces the long-distance migration of thousands of newly born neuroblasts from the SVZ to periinfarct cortex. These cells originate from GFAP-expressing progenitor cells in the SVZ and form close associations with periinfarct blood vessels in a region of active vascular remodeling, in which angiogenesis is causally linked to post-stroke neurogenesis. Blood vessels in peri-infarct cortex express SDF1 and Ang1, and their neighboring neuroblasts express their receptors CXCR4 and Tie2. Gain- and loss-of-function experiments within the SDF1 and Ang1 systems demonstrate distinct roles in promoting poststroke neuroblast migration and localization within peri-infarct cortex. Systemic administration of SDF1 $\beta$ and Ang1 promote behavioral recovery during the period of neuroblast migration but do not affect the long-term survival of regenerated neurons in peri-infarct cortex. These data define a unique neurovascular niche in peri-infarct cortex in which angiogenesis and neurogenesis are linked through specific vascular growth factors and chemokines in a process that is associated with behavioral recovery. The properties of this neurovascular niche indicate that injuryinduced CNS regeneration shares similar cellular features with normal neurogenesis in the CNS (Leventhal et al., 1999; Alvarez-Buylla and Lim, 2004; Wurmser et al., 2004) and with vascular/ stem cell niches in other organ systems (Fuchs et al., 2004).

Multipotent GFAP-expressing progenitor cells are the primary source of adult neurogenesis in the SVZ and SGZ (Garcia et al., 2004; Alvarez-Buylla and Lim, 2004). Previous studies have suggested that ischemia induces proliferation of neural stem cells in the SVZ and migration of neuroblasts to regions of damage (Jin et al., 2001, 2003; Arvidsson et al., 2002; Parent et al., 2002; Zhang et al., 2004; Tsai et al., 2006). Stroke damage adjacent to the SVZ induces neuroblast migration from GFAPexpressing progenitor cells (Yamashita et al., 2006). Alternatively, after cardiac, limb, or brain ischemia, bone marrowderived cells or EPCs are mobilized into the peripheral circulation, in which they proliferate and give rise to local endothelial cells, macrophage or microglial cells after stroke, and pericytes (Zhang et al., 2002; Hess et al., 2004; Kokovay et al., 2006). Circulating EPCs may also give rise to new neurons after stroke (Hess et al., 2004). The present study uses BrdU and lentiviral labeling within the SVZ, cell morphology, DCX staining, and the exclusion of markers for other cell types to identify these migrating post-stroke cells as immature neurons that are born within the SVZ and migrate up to $4 \mathrm{~mm}$ into peri-infarct cortex. Furthermore, we combined two transgenic targeting strategies to determine that post-stroke neurogenesis and neuroblast migration derives from a GFAP-expressing progenitor in the SVZ and not a VE-cadherin-expressing EPC.

Neurogenesis and angiogenesis are closely linked in the germinal zones of the adult brain. Neural progenitor cells lie in close proximity to endothelial cells, bursts of angiogenesis occur at the same time as neurogenesis, and endothelial cells secrete soluble factors that regulate neuronal differentiation in vitro (Alvarez- 
Buylla and Lim, 2004; Shen et al., 2004; Wurmser et al., 2004). These findings have led to the concept of a neurovascular niche that supports neurogenesis in the adult (Alvarez-Buylla and Lim, 2004; Wurmser et al., 2004) and is similar to the vascular and progenitor cell associations in stem cell niches of other organs (Fuchs et al., 2004). Neuroblasts migrate in association with blood vessels in the striatum after stroke (Yamashita et al., 2006). The present data show that neuroblasts ensheath and interdigitate with vascular endothelial cells specifically in areas of vascular remodeling, sprouting, and angiogenesis. This interaction is, at least in part, mediated by the vascular ligands SDF1 $\beta$ and Ang1 acting on neuroblast CXCR4 and Tie 2 receptors, which exert a tropic effect on migrating neuroblasts. Previous studies have identified a link between angiogenesis and neurogenesis after stroke using xeontransplants of human progenitor cells or transplants of conditionally immortalized cells after stroke (Imitola et al., 2004; Kelly et al., 2004; Taguchi et al., 2004) but have not addressed the mechanisms of normal or endogenous poststroke neurogenesis. The present data provide cellular and pharmacological evidence for a distinct type of neurovascular niche and associated chemokine/growth factor signaling in peri-infarct cortex. However, unlike the vascular association of early neuronal progenitor cells in the SVZ and SGZ, neurovascular coupling in peri-infarct cortex occurs between more differentiated, migrating neuroblasts and a vascular endothelium that is remodeling after injury. These differences suggest that molecular signaling in the post-stroke neurovascular niche may diverge from that seen in the neurovascular niche within these neural stem cell sites.

Although this report is the first causal link between endogenous angiogenesis and neurogenesis after stroke, other studies have noted a link between vascular markers or growth factors and neurogenesis after stroke (Wang et al., 2004b; Greenberg and Jin, 2005; Jin et al., 2006; Tsai et al., 2006; Robin et al., 2006). Animal strains with reduced angiogenesis (Wang et al., 2004a) do not show long-distance neuroblast migration (Komitova et al., 2005). Despite the vascular/neurogenesis associations in these studies and the present data, it has also been reported that stroke induces neuroblasts to associate with astrocytes as they migrate into damaged tissue in some stroke models. For example, in the ischemic striatum, neuroblasts associate with astrocytes, and it is these cells that provide a source of SDF1 (Thored et al., 2006). Intraventricular epidermal growth factor stimulates astrocytes to physically associate with migrating neuroblasts within the damaged striatum after stroke (Teramoto et al., 2003). The difference between the reports of neuroblast and

C

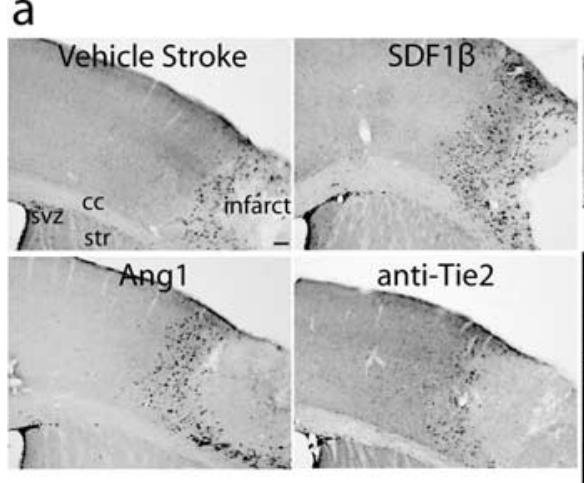
Peri-infarct DCX+ Cells

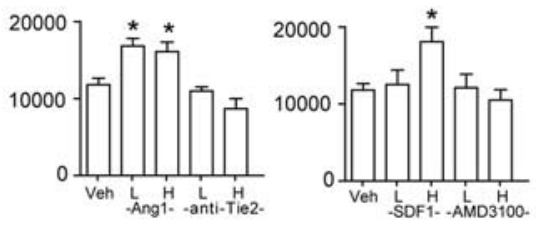

d $\mathrm{DCX}+$ Cell Volume $\left(\mathrm{mm}^{3}\right)$

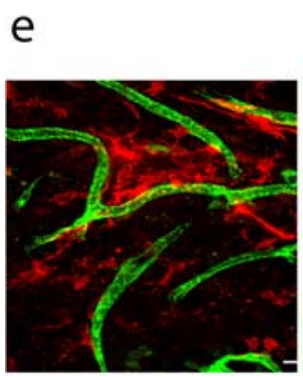

$f$
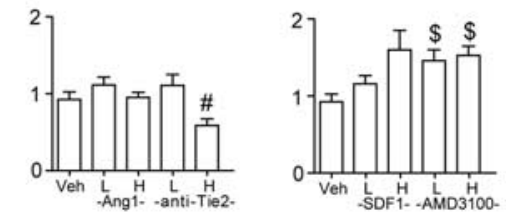

g
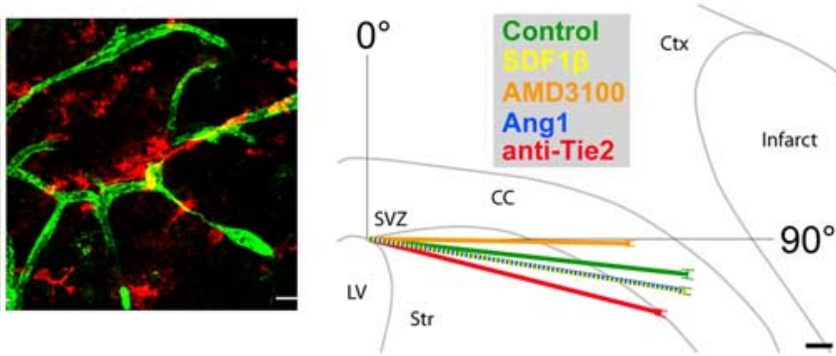

Figure 7. Ang1 and SDF1 $\beta$ gain- and loss-of-function experiments within neurovascular niche. $\boldsymbol{a}_{,} \mathrm{DCX}{ }^{+}$cells, stained with $D A B$, in peri-infarct cortex of vehicle-treated and Ang1 and SDF1 $\beta$ gain- and loss-of-function animals at day 7 after stroke. Scale bar, $100 \mu \mathrm{m} . \boldsymbol{b}, D_{C X}{ }^{+}$cells in subcortical white matter of vehicle-, SDF1 $\beta$-, and AMD3100-treated animals at day 7 after stroke. Arrows indicate the aberrant linear cluster of $D C X^{+}$cells along the striatum/white matter interface in AMD3100-treated stroke animals. Scale bar, $100 \mu \mathrm{m}$. c, Stereological quantification of $D C X^{+}$cells in peri-infarct cortex of Ang1 (left) and SDF1 $\beta$ (right) gain- and loss-of-function animals at day 7 after stroke. $p<0.68$ after low-dose SDF1 $\beta ; p=0.04$ for high-dose anti-Tie2 versus vehicle, not significant by Bonferroni's post hoc testing after Ang1. $\boldsymbol{d}$, Volume of DCX ${ }^{+}$cell distribution in peri-infarct cortex of Ang1 (left) and SDF1 $\beta$ (right) gain- and loss-of-function animals at day 7 after stroke. $p<0.01$ after high-dose SDF1 $\beta ; p<0.015$ for high-dose anti-Tie2 versus low dose after Ang1. For $\boldsymbol{c}$ and $\boldsymbol{d}, \mathrm{H}$ and $\mathrm{L}$ indicate high and low doses, and Veh is vehicle-treated. ${ }^{*} p<0.016$; ${ }^{\#} p<0.015 ;{ }^{\$} p<0.009$. $\boldsymbol{e}, \boldsymbol{f}$, SDF1 $\beta(\boldsymbol{e})$ and Ang1 $(\boldsymbol{f})$ treatment induce a clustering of DCX ${ }^{+}$cells (red) around PECAM- ${ }^{+}$blood vessels (green). Scale bars, $25 \mu \mathrm{m}$. $g$, Summary of migration vector analysis in subcortical white matter at day 7 after stroke. The position of $D C X^{+}$cells in white matter in each treatment condition was digitized and rendered as a polar plot with a vector angle $(\theta)$ and a vector length $(r)$. Each vector shows the mean angle and vector length of $D C X^{+}$cell migration in the indicated treatment conditions. The underlying outline is traced from a representative cresyl violet section through frontal cortex after stroke. The vector tips are bracketed by the SD for each mean. Note the vector for SDF1 $\beta$ is dashed to be visible as it overlaps with the Ang1 vector. The complete distribution of migratory angles is presented in histograms for each treatment condition in supplemental Figure 2 (available at www.jneurosci.org as supplemental material). Scale bar, $100 \mu \mathrm{m}$. Error bars in all panels indicate SD. cc, Corpus callosum; ctx, cortex; Iv, lateral ventricle; str, striatum; veh, vehicle. astrocyte associations in these stroke studies, and the findings of a neurovascular niche in the present study, may relate to differences in the distribution of stroke damage. The association of astrocytes with migrating neuroblasts is present when neuroblasts are migrating within damaged and scarring striatal tissue (Teramoto et al., 2003; Thored et al., 2006). In the present study, neuroblasts migrated a long distance through undamaged striatum and white matter before associating with blood vessels in peri-infarct cortex. It is likely that the microenvironments adjacent to the SVZ differ substantially between these two conditions and that neuroblasts may associate locally with astrocytes when 

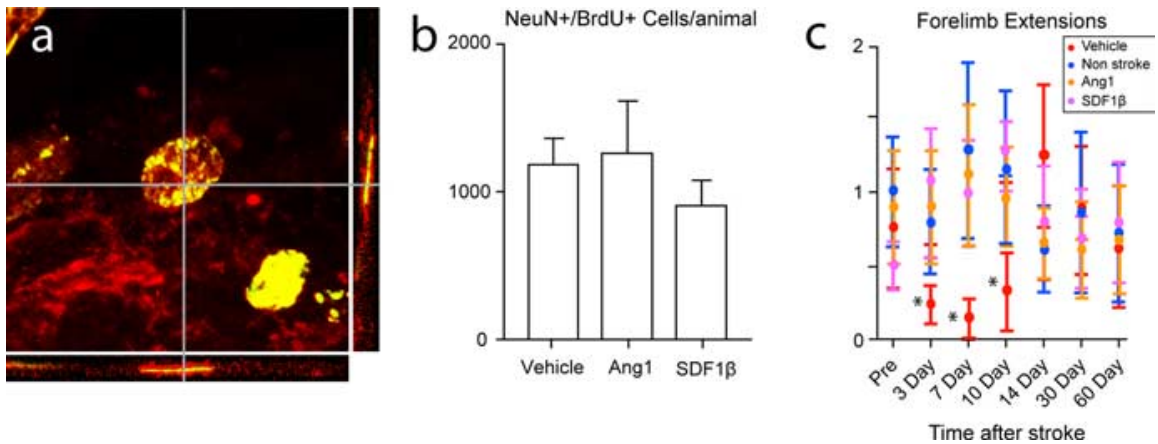

Figure 8. Ang1 and SDF1 $\beta$ improve behavioral recovery after stroke. $\boldsymbol{a}$, Example of stroke-generated cell double labeled for NeuN (red) and BrdU (green) with significant overlap (yellow) at $90 \mathrm{~d}$ after stroke. The three-dimensional confocal reconstruction is presented as viewed in the $x-z$ (bottom) and $y-z$ (right) planes. $\boldsymbol{b}$, Stereological quantification of $\mathrm{NeuN}^{+} / \mathrm{BrdU}^{+}$cells in peri-infarct cortex at day 90 after stroke after vehicle, Ang1, or SDF1 $\beta$ treatment. $1183 \pm 386$ per animal after vehicle; $906 \pm 420$ after SDF1 $\beta ; 1260 \pm 842$ after Ang1. $p>0.32$. c, Behavioral recovery after stroke as tested on a whisker-guided forelimb extension task. ${ }^{*} p<0.05$. Error bars in all graphs indicate SD.

the damage abuts the SVZ but migrate toward vascular sources of growth factors and chemokines when the damage is distant from the SVZ.

The cerebral vasculature responds to focal ischemia through changes in the gene expression profile of vascular endothelial cells, including new patterns of cell adhesion molecules, vascular growth factors, and chemokines (Abumiya et al., 1999; Stumm et al., 2002). Our findings show that stroke induces a wave of expression of the chemokine SDF1 and the vascular growth factor Ang1 in peri-infarct blood vessels. These molecules have a role in cellular differentiation and migration within non-neural stem cell niches in the body (Arai et al., 2004; Avecilla et al., 2004). Because stroke opens the BBB in peri-infarct cortex, we were able to deliver these ligands and their antagonists systemically but with selective penetration to the target zone of post-stroke neurogenesis. SDF1 $\beta$ administration recruits thousands more neuroblasts to peri-infarct cortex. Blockade of the SDF1 receptor CXCR4 does not alter the number of migrating neuroblasts but causes dispersal of these cells and a highly abnormal migration pattern. These data clearly place SDF1 $\beta$ as a neuroblast tropic or directional factor within peri-infarct cortex after stroke. Ang1 administration also recruited more neuroblasts to peri-infarct cortex, and blockade of its receptor Tie2 reduced neuroblast volume and trended toward a reduced neuroblast number. Tie2 blockade produced a significant, lateral deviation of neuroblast migration through white matter that is opposite to the effect of CXCR4 blockade. The differences between SDF1 and Ang1 in post-stroke neurogenesis may relate to distinct mechanisms of neuroblast recruitment or interactions with other vascular growth factors, particularly between Ang1 and VEGF (DeBusk et al., 2004).

Ang1 and SDF1 $\beta$ improve behavioral recovery after stroke. This behavioral improvement is seen in forelimb and whisker function in a task (Gerlai et al., 2000) that uses the cortical region in which newly born neuroblasts migrate in this stroke model (Tsai et al., 2006). Importantly, the behavioral improvement with SDF1 $\beta$ and Ang1 occurs only during the first $10 \mathrm{~d}$ after stroke, during the period in which these molecules recruit thousands of additional neuroblasts into peri-infarct cortex. This early effect of neuroblast migration on cortical function after stroke suggests that the improved behavioral recovery is not attributable to the formation of new neuronal circuits in peri-infarct cortex from newly born neurons. Indeed, there was no change in long-term survival of newly born cells in peri-infarct cortex with chemokine or growth factor treatment. Neural progenitor cells secrete several cytokines and growth factors, including BDNF and FGF (Mi et al., 2005). Because neurons in periinfarct cortex experience delayed cell injury and abnormal patterns of synaptic transmission (Witte et al., 2000), newly born neuroblasts may improve behavioral recovery after stroke by stabilizing injured or synaptically dysfunctional neurons in peri-infarct tissue. Enhancing post-stroke neurogenesis may be a mechanism to provide a local growth factor source in periinfarct cortex that sustains injured neuronal circuits in the first weeks after stroke.

\section{References}

Abumiya T, Lucero J, Heo JH, Tagaya M, Koziol JA, Copeland BR, del Zoppo GJ (1999) Activated microvessels express vascular endothelial growth factor and integrin alpha $(\mathrm{v})$ beta3 during focal cerebral ischemia. J Cereb Blood Flow Metab 19:1038-1050.

Aguirre A, Gallo V (2004) Postnatal neurogenesis and gliogenesis in the olfactory bulb from NG2-expressing progenitors of the subventricular zone. J Neurosci 24:10530-10541.

Alva JA, Zovein AC, Monvoisin A, Murphy T, Salazar A, Harvey NL, Carmeliet P, Iruela-Arispe ML (2006) VE-Cadherin-Cre-recombinase transgenic mouse: a tool for lineage analysis and gene deletion in endothelial cells. Dev Dyn 235:759-767.

Alvarez-Buylla A, Lim DA (2004) For the long run: maintaining germinal niches in the adult brain. Neuron 41:683-686.

Arai F, Hirao A, Ohmura M, Sato H, Matsuoka S, Takubo K, Ito K, Koh GY, Suda T (2004) Tie2/angiopoietin-1 signaling regulates hematopoietic stem cell quiescence in the bone marrow niche. Cell 118:149-161.

Arvidsson A, Collin T, Kirik D, Kokaia Z, Lindvall O (2002) Neuronal replacement from endogenous precursors in the adult brain after stroke. Nat Med 8:963-970.

Avecilla ST, Hattori K, Heissig B, Tejada R, Liao F, Shido K, Jin DK, Dias S, Zhang F, Hartman TE, Hackett NR, Crystal RG, Witte L, Hicklin DJ, Bohlen P, Eaton D, Lyden D, de Sauvage F, Rafii S (2004) Chemokinemediated interaction of hematopoietic progenitors with the bone marrow vascular niche is required for thrombopoiesis. Nat Med 10:64-71.

Brown JP, Couillard-Despres S, Cooper-Kuhn CM, Winkler J, Aigner L, Kuhn HG (2003) Transient expression of doublecortin during adult neurogenesis. J Comp Neurol 467:1-10.

Carmichael ST (2005) Rodent models of focal stroke: size, mechanism, and purpose. NeuroRx 2:396-409.

Carmichael ST, Wei L, Rovainen CM, Woolsey TA (2001) New patterns of intracortical projections after focal cortical stroke. Neurobiol Dis 8:910-922.

Casella GT, Marcillo A, Bunge MB, Wood PM (2002) New vascular tissue rapidly replaces neural parenchyma and vessels destroyed by a contusion injury to the rat spinal cord. Exp Neurol 173:63-76.

Couillard-Despres S, Winner B, Schaubeck S, Aigner R, Vroemen M, Weidner N, Bogdahn U, Winkler J, Kuhn HG, Aigner L (2005) Doublecortin expression levels in adult brain reflect neurogenesis. Eur J Neurosci 21:1-14

Dancause N, Barbay S, Frost SB, Plautz EJ, Chen D, Zoubina EV, Stowe AM, Nudo RJ (2005) Extensive cortical rewiring after brain injury. J Neurosci 25:10167-10179.

De Clercq E (2000) Inhibition of HIV infection by bicyclams, highly potent and specific CXCR4 antagonists. Mol Pharmacol 57:833-839.

DeBusk LM, Hallahan DE, Lin PC (2004) Akt is a major angiogenic mediator downstream of the Ang1/Tie2 signaling pathway. Exp Cell Res 298:167-177.

Dobryansky M, Galiano RD, Cetrulo Jr CL, Bhatt KA, Michaels J, Ashinoff R, Levine JP, Gurtner GC (2004) Endostatin inhibits ischemia-induced neovascularization and increases ischemic tissue loss. Ann Plast Surg 52:512-518. 
Folkman J, Browder T, Palmblad J (2001) Angiogenesis research: guidelines for translation to clinical application. Thromb Haemost 86:23-33.

Fuchs E, Tumbar T, Guasch G (2004) Socializing with the neighbors: stem cells and their niche. Cell 116:769-778.

Garcia AD, Doan NB, Imura T, Bush TG, Sofroniew MV (2004) GFAPexpressing progenitors are the principal source of constitutive neurogenesis in adult mouse forebrain. Nat Neurosci 7:1233-1241.

Gerlai R, Thibodeaux H, Palmer JT, van Lookeren Campagne M, Van Bruggen N (2000) Transient focal cerebral ischemia induces sensorimotor deficits in mice. Behav Brain Res 108:63-71.

Greenberg DA, Jin K (2005) From angiogenesis to neuropathology. Nature 438:954-959.

Gritti A, Bonfanti L, Doetsch F, Caille I, Alvarez-Buylla A, Lim DA, Galli R, Verdugo JM, Herrera DG, Vescovi AL (2002) Multipotent neural stem cells reside into the rostral extension and olfactory bulb of adult rodents. J Neurosci 22:437-445.

Hashizume H, Baluk P, Morikawa S, McLean JW, Thurston G, Roberge S, Jain RK, McDonald DM (2000) Openings between defective endothelial cells explain tumor vessel leakiness. Am J Pathol 156:1363-1380.

Herodin F, Bourin P, Mayol JF, Lataillade JJ, Drouet M (2003) Short-term injection of antiapoptotic cytokine combinations soon after lethal gamma-irradiation promotes survival. Blood 101:2609-2616.

Hess DC, Abe T, Hill WD, Studdard AM, Carothers J, Masuya M, Fleming PA, Drake CJ, Ogawa M (2004) Hematopoietic origin of microglial and perivascular cells in brain. Exp Neurol 186:134-144.

Hristov M, Weber C (2004) Endothelial progenitor cells: characterization, pathophysiology, and possible clinical relevance. J Cell Mol Med 8:498-508.

Imitola J, Raddassi K, Park KI, Mueller FJ, Nieto M, Teng YD, Frenkel D, Li J, Sidman RL, Walsh CA, Snyder EY, Khoury SJ (2004) Directed migration of neural stem cells to sites of CNS injury by the stromal cell-derived factor 1alpha/CXC chemokine receptor 4 pathway. Proc Natl Acad Sci USA 101:18117-18122.

Jin K, Minami M, Lan JQ, Mao XO, Batteur S, Simon RP, Greenberg DA (2001) Neurogenesis in dentate subgranular zone and rostral subventricular zone after focal cerebral ischemia in the rat. Proc Natl Acad Sci USA 98:4710-4715.

Jin K, Sun Y, Xie L, Peel A, Mao XO, Batteur S, Greenberg DA (2003) Directed migration of neuronal precursors into the ischemic cerebral cortex and striatum. Mol Cell Neurosci 24:171-189.

Jin K, Wang X, Xie L, Mao XO, Zhu W, Wang Y, Shen J, Mao Y, Banwait S, Greenberg DA (2006) Evidence for stroke-induced neurogenesis in the human brain. Proc Natl Acad Sci USA 103:13198-13202.

Jones N, Iljin K, Dumont DJ, Alitalo K (2001) Tie receptors: new modulators of angiogenic and lymphangiogenic responses. Nat Rev Mol Cell Biol 2:257-267.

Kelly S, Bliss TM, Shah AK, Sun GH, Ma M, Foo WC, Masel J, Yenari MA, Weissman IL, Uchida N, Palmer T, Steinberg GK (2004) Transplanted human fetal neural stem cells survive, migrate, and differentiate in ischemic rat cerebral cortex. Proc Natl Acad Sci USA 101:11839-11844.

Kirschenbaum B, Doetsch F, Lois C, Alvarez-Buylla A (1999) Adult subventricular zone neuronal precursors continue to proliferate and migrate in the absence of the olfactory bulb. J Neurosci 19:2171-2180.

Kokovay E, Li L, Cunningham LA (2006) Angiogenic recruitment of pericytes from bone marrow after stroke. J Cereb Blood Flow Metab 26:545-555.

Komitova M, Zhao LR, Gido G, Johansson BB, Eriksson P (2005) Postischemic exercise attenuates whereas enriched environment has certain enhancing effects on lesion-induced subventricular zone activation in the adult rat. Eur J Neurosci 21:2397-2405.

Leventhal C, Rafii S, Rafii D, Shahar A, Goldman SA (1999) Endothelial trophic support of neuronal production and recruitment from the adult mammalian subependyma. Mol Cell Neurosci 13:450-464.

Li YQ, Chen P, Haimovitz-Friedman A, Reilly RM, Wong CS (2003) Endothelial apoptosis initiates acute blood-brain barrier disruption after ionizing radiation. Cancer Res 63:5950-5956.

Louissaint Jr A, Rao S, Leventhal C, Goldman SA (2002) Coordinated interaction of neurogenesis and angiogenesis in the adult songbird brain. Neuron 34:945-960.

Mi R, Luo Y, Cai J, Limke TL, Rao MS, Hoke A (2005) Immortalized neural stem cells differ from nonimmortalized cortical neurospheres and cerebellar granule cell progenitors. Exp Neurol 194:301-319.
Parent JM, Vexler ZS, Gong C, Derugin N, Ferriero DM (2002) Rat forebrain neurogenesis and striatal neuron replacement after focal stroke. Ann Neurol 52:802-813.

Paxinos G, Franklin KBJ (2001) Mouse brain in stereotaxic coordinates. San Diego: Academic.

Robin AM, Zhang ZG, Wang L, Zhang RL, Katakowski M, Zhang L, Wang Y, Zhang C, Chopp M (2006) Stromal cell-derived factor 1alpha mediates neural progenitor cell motility after focal cerebral ischemia. J Cereb Blood Flow Metab 26:125-134.

Roviezzo F, Tsigkos S, Kotanidou A, Bucci M, Brancaleone V, Cirino G, Papapetropoulos A (2005) Angiopoietin-2 causes inflammation in vivo by promoting vascular leakage. J Pharmacol Exp Ther 314:738-744.

Shen Q, Goderie SK, Jin L, Karanth N, Sun Y, Abramova N, Vincent P, Pumiglia K, Temple S (2004) Endothelial cells stimulate self-renewal and expand neurogenesis of neural stem cells. Science 304:1338-1340.

Stumm RK, Rummel J, Junker V, Culmsee C, Pfeiffer M, Krieglstein J, Hollt V, Schulz S (2002) A dual role for the SDF-1/CXCR4 chemokine receptor system in adult brain: isoform-selective regulation of SDF-1 expression modulates CXCR4-dependent neuronal plasticity and cerebral leukocyte recruitment after focal ischemia. J Neurosci 22:5865-5878.

Taguchi A, Soma T, Tanaka H, Kanda T, Nishimura H, Yoshikawa H, Tsukamoto Y, Iso H, Fujimori Y, Stern DM, Naritomi H, Matsuyama T (2004) Administration of $\mathrm{CD} 34+$ cells after stroke enhances neurogenesis via angiogenesis in a mouse model. J Clin Invest 114:330-338.

Teramoto T, Qiu J, Plumier JC, Moskowitz MA (2003) EGF amplifies the replacement of parvalbumin-expressing striatal interneurons after ischemia. J Clin Invest 111:1125-1132.

Thored P, Arvidsson A, Cacci E, Ahlenius H, Kallur T, Darsalia V, Ekdahl CT, Kokaia Z, Lindvall O (2006) Persistent production of neurons from adult brain stem cells during recovery after stroke. Stem Cells 24:739-747.

Tsai PT, Ohab JJ, Kertesz N, Groszer M, Matter C, Gao J, Liu X, Wu H, Carmichael ST (2006) A critical role of erythropoietin receptor in neurogenesis and post-stroke recovery. J Neurosci 26:1269-1274.

Veltkamp R, Siebing DA, Sun L, Heiland S, Bieber K, Marti HH, Nagel S, Schwab S, Schwaninger M (2005) Hyperbaric oxygen reduces bloodbrain barrier damage and edema after transient focal cerebral ischemia. Stroke 36:1679-1683.

Wang H, Olszewski B, Rosebury W, Wang D, Robertson A, Keiser JA (2004a) Impaired angiogenesis in SHR is associated with decreased KDR and MT1-MMP expression. Biochem Biophys Res Commun 315:363-368.

Wang L, Zhang Z, Wang Y, Zhang R, Chopp M (2004b) Treatment of stroke with erythropoietin enhances neurogenesis and angiogenesis and improves neurological function in rats. Stroke 35:1732-1737.

Ware JA, Simons M (1997) Angiogenesis in ischemic heart disease. Nat Med 3:158-164.

Witte OW, Bidmon HJ, Schiene K, Redecker C, Hagemann G (2000) Functional differentiation of multiple perilesional zones after focal cerebral ischemia. J Cereb Blood Flow Metab 20:1149-1165.

Witzenbichler B, Maisonpierre PC, Jones P, Yancopoulos GD, Isner JM (1998) Chemotactic properties of angiopoietin-1 and -2, ligands for the endothelial-specific receptor tyrosine kinase Tie2. J Biol Chem 273:18514-18521.

Wurmser AE, Palmer TD, Gage FH (2004) Neuroscience. Cellular interactions in the stem cell niche. Science 304:1253-1255.

Yamashita T, Ninomiya M, Hernandez Acosta P, Garcia-Verdugo JM, Sunabori T, Sakaguchi M, Adachi K, Kojima T, Hirota Y, Kawase T, Araki N, Abe K, Okano H, Sawamoto K (2006) Subventricular zone-derived neuroblasts migrate and differentiate into mature neurons in the post-stroke adult striatum. J Neurosci 26:6627-6636.

Yu SW, Friedman B, Cheng Q, Lyden PD (2006) Stroke-evoked angiogenesis results in a transient population of microvessels. J Cereb Blood Flow Metab, in press.

Zhang R, Zhang Z, Zhang C, Zhang L, Robin A, Wang Y, Lu M, Chopp M (2004) Stroke transiently increases subventricular zone cell division from asymmetric to symmetric and increases neuronal differentiation in the adult rat. J Neurosci 24:5810-5815.

Zhang ZG, Zhang L, Jiang Q, Chopp M (2002) Bone marrow-derived endothelial progenitor cells participate in cerebral neovascularization after focal cerebral ischemia in the adult mouse. Circ Res 90:284-288. 